\title{
La Regulación del Lobbying: Una tarea pendiente en Ecuador
}

Lobbying Regulation: A pending task in Ecuador

Mtr. Víctor Augusto Espinosa Jácome

Investigador Jurídico Independiente

Artículo Original (Revisión)

RFJ, No. 4, 2018, pp. 53-86, ISSN 2588-0837

RESUMEN: este documento es un análisis de la regulación del lobbying como un mecanismo de participación política de los actores de la sociedad civil, desde las propuestas teóricas que consideran que la transparencia aporta a la legitimidad de esta actividad. En este artículo se utiliza una metodología analítica comparativa para demostrar que el ordenamiento jurídico ecuatoriano, a diferencia del chileno, peruano, argentino y colombiano, carece de instrumentos regulatorios para transparentar la influencia de los "grupos de presión" en los procesos de toma de decisiones públicas.

PALABRAS CLAVE: lobby, sociedad civil, democracia, regulación, política pública.

ABSTRACT: this paper analyze the lobbying regulation as a political participation mechanism acquired and commonly used by civil society. It draws a theoretical framework that argues how transparency contributes to lobbying legitimacy. Through an analytic comparative method, it is the aim of the article to prove lack of instruments within the Ecuadorian legal system, in contrast with the Chilean, Peruvian, Argentines and Colombian law, in order to foster transparency of interest groups influence.

KEY WORDS: lobby, civil society, democracy, regulation, public politics. 


\section{INTRODUCCIÓN}

En el contexto de la globalización, los instrumentos regulatorios de los Estados nacionales van perdiendo eficacia ante las nuevas dinámicas económicas. Así mismo, los mecanismos tradicionales de la democracia representativa son insuficientes para procesar las demandas sociales. Una de las respuestas a esta problemática es la teoría de la gobernanza. De acuerdo con estos postulados, existe una ruptura entre el Derecho y las relaciones económicas que no la pueden saldar ni los Estados ni el mercado, por sí solos. En consecuencia, una de las soluciones a este dilema sería la participación de la sociedad civil en los procesos de toma de decisiones públicas mediante la conformación de redes colaborativas que incluyen a las corporaciones y a las asociaciones civiles v. (Sousa Santos y Rodríguez Garavito, 2007).

Para que estas redes asociativas tengan éxito se requiere que los ordenamientos jurídicos garanticen mecanismos participativos mediante los cuales, los grupos de la sociedad civil puedan incidir en las decisiones públicas. De esta forma, la interacción de este tercer sector con los actores del Estado y el mercado generaría los equilibrios necesarios para unas relaciones económicas que garanticen el interés general $v$. (Rubio, 2007).

En abstracto, el lobbying es la influencia que ejercen los "grupos de presión” en las decisiones legislativas o en la formulación de políticas públicas $v$. (Ridao, 2017). La doctrina define el término "grupo de presión" como un conjunto de personas organizadas que pretende influir en los cargos públicos en beneficio de sus intereses. En este mismo sentido, la Comisión para la Democracia por medio del Derecho del Consejo de Europa (Comisión de Venecia) aclara que se tratan actores extrainstitucionales, por lo que los define de las siguiente manera: "personas o entidades que no actúan en el ejercicio de una autoridad pública o mandato constitucional" (European Comission for Democracy Through Law, 2013, pág. 4). De estos conceptos se deduce que este sector es parte de la sociedad civil. Por lo tanto, el lobbying se incluye entre los mecanismos participativos que se promueven desde la gobernanza.

Una de las principales discusiones en torno al lobbying tiene que ver con su legalidad. Lo que se debate es si esta actividad implica necesariamente la comisión de delitos como el tráfico de influencia, el cohecho, o el beneficiarse de información privilegiada. Esto se asocia a las intenciones ocultas que tendrían ciertos "grupos de presión" y a que 
los intereses particulares que defienden podrían ser contrarios al interés general. En este mismo sentido, se plantea como un mecanismo permeable a las prácticas corruptas.

Los delitos relacionados con la corrupción están prohibidos por la legislación penal. No obstante, no todas las actividades que abarca la definición abstracta de lobbying implican una práctica delictiva. Por lo tanto, cuando no se incurre en una infracción, no solo que se trata de una práctica legal, sino que es un mecanismo mediante el cual los "grupos de presión" ejercen sus derechos de participación para defender sus intereses.

Otro de los dilemas que plantea el lobbying es sobre su legitimidad. El principal cuestionamiento al respecto es que la representatividad de los "grupos de presión" no proviene de los mecanismos electorales tradicionales. La pluralidad de los actores que pretenden influir en las decisiones públicas dificulta apreciar la compatibilidad de sus pretensiones con el interés general y el grado de convergencia de sus exigencias con las verdaderas demandas de los sectores sociales que argumentan representar.

En este sentido, las teorías críticas a la gobernanza sostienen que en los procesos participativos se imponen los intereses de los actores dominantes en el mercado y se termina excluyendo a los sectores mayoritarios de la sociedad. Por lo tanto, estos mecanismos no estarían cumpliendo con el objetivo de equilibrar las relaciones entre Estado, mercado y sociedad civil; sino que únicamente serían útiles para darle una falsa legitimidad a la desregulación v. (Sousa Santos \& Rodríguez Garavito, 2007).

Una de las soluciones que se plantea ante estos cuestionamientos es incorporar instrumentos que transparenten estos procesos participativos. Para compatibilizar el lobbying con la democracia, ciertos sectores sugieren que estas actividades sean identificables para la ciudadanía. Por ejemplo, el reporte On The Role Of Extra-Institutional Actors In The Democratic System (Lobbying) de la Comisión de Venecia concluye que para cumplir con los estándares democráticos es necesario que se incorpore legislación que garantice la transparencia $v$. (European Comission for Democracy Through Law, 2013).

La regulación del lobbying no es un fenómeno nuevo en Estados Unidos. El ordenamiento jurídico estadounidense cuenta con legislación sobre la materia desde 1946. Sin embargo, este tema es relativamente reciente en la agenda política de los demás países. Durante el siglo XX, solo Canadá y Australia se sumaron a la lista de Estados en los que esta discusión tuvo 
relevancia en la opinión pública. Es desde principios de siglo que este tópico empieza a debatirse en Europa y Latinoamérica v. (Córdova, 2017).

A nivel de Sudamérica, solo en Chile y Perú se han promulgado leyes específicas sobre lobbying. En Colombia se introdujo en la Constitución el mandato de regular el cabildeo, existe un proyecto de ley en trámite y una Resolución de la Cámara de Representantes, aplicable solo para este organismo v.(Córdova, 2017). Así mismo, los parlamentos de Brasil v. (Cristaldo y Brito, 2017) y Argentina v. (Arbia, 2017) se encuentran gestionando propuestas normativas al respecto. Actualmente, el ordenamiento jurídico argentino prevé un decreto del Presidente de la República que reglamenta "la gestión de intereses", pero se restringen únicamente al poder ejecutivo federal $v$. (Novaro, 2015).

Si se tiene en cuenta este marco teórico, la hipótesis de la cual parte el presente artículo es que el ordenamiento jurídico ecuatoriano carece de instrumentos jurídicos suficientes para transparentar el lobbying. Con el objetivo de demostrar este postulado, se utiliza un método de investigación analítico comparativo para revisar el estado de la legislación sobre esta materia en Ecuador; en contraste con la de Chile, Perú, Colombia, Argentina y Brasil.

Para alcanzar esta finalidad, en el primer epígrafe del este artículo se profundiza en los conceptos relacionados con el lobbying y en la discusión teórica sobre su legitimidad. En una segunda parte se analiza los instrumentos participativos que prevé el ordenamiento jurídico ecuatoriano para constatar que son insuficientes para regular esta práctica. Finalmente, se revisa, como referencia, la legislación sobre la materia de los países sudamericanos señalados en el párrafo anterior.

\section{CONCEPTOS RELACIONADOS CON EL LOBBYING Y DIS- CUSIÓN TEÓRICA SOBRE SU LEGITIMIDAD}

\section{1. ¿Qué es el lobbying?}

Los conceptos de lobbying previstos en la doctrina, los instrumentos de derecho blando y la legislación de los países sudamericanos no presentan divergencias relevantes entre sí. Una acepción amplia de esta actividad es la siguiente: "Presión organizada frente al Poder Público" (Córdova, 2017, pág. 19). En este mismo sentido, la definición 
de la OCDE es la siguiente: "Cualquier comunicación directa o indirecta con agentes públicos o representantes políticos con la finalidad de influenciar la toma de una decisión pública, desarrollada por o en nombre de un grupo organizado" (OECD, 2013). Mientras tanto, en el Libro Verde de la Iniciativa Europea en Favor de la Transparencia de la Unión Europea se entiende esta práctica como lo subsecuente: "todas las actividades que se realicen con el objetivo de influir en los procesos de elaboración de políticas y de toma de decisiones de las instituciones europeas" (Comisión Comunidades Europeas, 2006, pág. 5). Las definiciones generales de lobbying son tan amplias que podrían abarcar incluso prácticas corruptas, sancionadas por las legislaciones penales. Sin embargo, la influencia en el proceso de toma de decisiones de los cargos públicos, no implica un delito en todos los casos. Incluso, cuando se excluyen los actos delictivos, esto es un instrumento legítimo de participación democrática. Por lo tanto, estas conductas deben ser diferenciadas.

Sería equivocado sostener que la regulación sobre el lobbying, entendida genéricamente, excluye a los delitos. La legislación en materia penal también es un instrumento regulatorio. Por lo tanto, estas conductas, que están incluidas en la definición más abstracta del concepto lobbying, son reguladas por el ordenamiento jurídico mediante su prohibición. No obstante, la aproximación de la presente investigación a este fenómeno no es desde el Derecho Penal. En consecuencia, los actos delictivos no son parte del objeto de estudio.

Como se mencionó en la Introducción, los ordenamientos jurídicos de algunos países de Sudamérica no se han limitado a prohibir el lobbying ilegal, sino que también regulan las prácticas no delictivas. Estas normas jurídicas contienen conceptos similares a los indicados en los párrafos anteriores, pero que, por su finalidad, se entiende que abarcan únicamente la acepción de esta actividad que no está proscrita por la legislación penal. En la Ley 28024 que regula la Gestión de Intereses en la Administración Pública de Perú, al lobbying se lo denomina "gestión de intereses" y se lo define así1"

La actividad mediante la cual personas naturales o jurídicas, nacionales o extranjeras, promueven de manera transparente sus puntos de vista en el proceso de decisión pública, a fin de orientar dicha decisión en el sentido deseado por ellas.

12 Perú. (2003). Ley N. 28024 que regula la gestión de intereses en la administración pública. 
De igual manera, el Decreto 1172/2003 argentino, que regula la "gestión de intereses" en el poder ejecutivo, la define de la siguiente forma ${ }^{13}$ :

Toda actividad desarrollada - en modalidad de audiencia - con personas físicas o jurídicas, públicas o privadas, por sí o en representación de terceros - con o sin fines de lucro - cuyo objeto consista en influir en el ejercicio de cualquiera de las funciones y/o decisiones de los organismos, entidades, empresas, sociedades, dependencias y de todo otro ente que funciones bajo la jurisdicción del Poder Ejecutivo Nacional.

La definición de "gestión de intereses" prevista en el literal a) del artículo 2 del Proyecto de Ley Gestión de Intereses argentino ${ }^{14}$, que se está tramitando en el parlamento, no presenta mayores discrepancias con la del Decreto 1172/ 2003. La diferencia más relevante no es en el concepto, sino en el ámbito de aplicación que no se limita únicamente al poder ejecutivo.

En el ordenamiento jurídico colombiano al lobbying se lo denomina "cabildeo". El artículo 12 de la Resolución N. MD-2348 de la Cámara de Representantes ${ }^{15}$, que crea un registro de cabilderos, prevé lo subsecuente:

Cabildeo: Todo esfuerzo -protegido constitucionalmente- y realizado por individuos o grupos de individuos, organizados autónomamente, para dar a conocer sus posiciones, en defensa de intereses particulares, en los procesos legislativos y en cualquier asunto propuesto por la Cámara de Representantes. El cabildeo podrá hacerse mediante la distribución de material impreso, la concurrencia a las diferentes comisiones y subcomisiones de la Cámara de Representantes, así como a entrevistas o intentos por entrevistar a miembros de esta Corporación Legislativa.

Al igual que en Argentina, el Proyecto de Ley para la Regulación del Cabildeo, que está siendo debatido en el legislativo colombiano,

13 Argentina. (2003). Decreto 1172/2003 Acceso a la Información Pública. Boletín Oficial No. 30291, p. 1.

14 Argentina, Jefatura de Gabinete de Ministros. (2017). Proyecto de Ley Gestión de Intereses. Mensaje No. 34.

15 Colombia. (2011). Resolución MD-2348 de 2011. Cámara de Representantes. Tomado de http://www.camara.gov.co/participacion-ciudadana/registro-publico-de-cabilderos. 
no presenta mayores diferencias en el concepto de lobbying con el de la Resolución N. MD-2348. El artículo 3 dispone que las "actividades de cabildeo" $\operatorname{sean}^{16}$ :

Toda comunicación que realice el cabildero para promover, defender o representar cualquier interés particular propio o de un cliente ante las autoridades frente a las decisiones que deban adoptar en el ejercicio de sus funciones. Lo anterior, incluye los esfuerzos tendientes a evitar la adopción de decisiones.

En el Proyecto de Ley 1202/2007 brasileño que tiene como objeto regular la "gestión de intereses" se dispone lo siguiente ${ }^{17}$ :

Lobby es la presión o esfuerzo deliberado para influenciar en una decisión administrativa o legislativa en un determinado sentido, favorable a entidades representativas de grupos de interés; o por parte alguien que actúa en defensa de intereses propios o de terceros, o en sentido contrario a los intereses de terceros..$^{18}$

La única novedad a nivel legislativo en relación con la definición del lobbying se presenta en el ordenamiento jurídico chileno. El artículo 2 de la Ley Núm. 20730 que regula el lobby y las gestiones que representan intereses particulares ante las autoridades y funcionarios diferencia el lobbying de la "gestión de interés particular". Para este primer concepto prevé la siguiente definición ${ }^{19}$ :

Aquella gestión o actividades remuneradas, ejercida por personas naturales o jurídicas, chilenas o extranjeras, que tiene por objeto promover, defender o representar cualquier interés particular para influir en las decisiones que, en el ejercicio de sus funciones, deban adoptar los sujetos pasivos que se indican en los artículos 3) y 4).

16 Colombia, Comisión Primera Cámara de Representantes. (2017). Ponencia para primer debaten en la Comisión Primera de la Cámara de Representantes de Proyecto de Ley No.296 de 2017 Cámara, 096 de 2016 de Senado "Por el cual se regula el ejericio de cabildeo y se dictan otras disposiciones."

17 Brasil. Camara dos Deputados. (2007). Informe de Tramitación Proyecto de Ley 1202/2007. Tomado de http://www.camara.gov.br/proposicoesWeb/fichadetramitacao?idProposicao=353631.

18 Traducido del portugués al castellano por el autor.

19 Chile. (2014). Ley 20730 que regula el lobby y las gestiones que representen intereses particulares ante las autoridades y funcionarios. Id Norma 1060115. 
Lo anterior incluye los esfuerzos específicos para influir en el proceso de toma de decisiones públicas y cambios en las políticas, planes o programas, en discusión o en desarrollo, o sobre cualquier medida implementada o materia que deba ser resuelta por el funcionario, la autoridad o el organismo público correspondiente, o bien para evitar tales decisiones, cambios y medidas.

La definición de "gestión de interés particular" es igual a la de lobbying. En este concepto únicamente se omite la palabra "remunerada". La intención del legislador es diferenciar las actividades que realizan directamente los "grupos de presión" de las ejecutadas mediante un prestador de servicios profesionales. Sin embargo, para efectos prácticos esta distinción no es relevante, ya que la regulación es la misma para ambas actividades.

En conclusión, tanto la doctrina como los instrumentos de derecho blando y la legislación de los países de Sudamérica coinciden en entender al lobbying en un concepto amplio que abarca las distintas formas de influencia de actores ajenos a las instituciones en la expedición de normas y de definición de políticas públicas.

Sin embargo, la OCDE (2012), señala que no hay una única definición de Lobbying en todos los países, pero "en cualquier definición que se considere, el concepto en común de todas ellas es el ejercicio de la influencias, entendido por influencia promover, defender oponerse o retrasar una decisión a través de diferentes medios, incluida la aportación o utilización de informaciones y estadisticas".

Por lo tanto, en términos generales, esta práctica es toda acción realizada con el objetivo de incidir en el proceso de toma de decisiones de un organismo o funcionario público.

\section{2. ¿Quiénes hacen lobbying?}

Otro de los conceptos relevantes relacionados con el lobbying es el de los actores que realizan y se benefician de estas prácticas. La posición mayoritaria en la doctrina y desde la cual parten los instrumentos de regulación tiende a agrupar a todos estos sujetos bajo la denominación de "grupos de presión" o sus equivalentes. Por ejemplo, como se mencionó en la Introducción, la Comisión de Venecia los denomina como "actores extrainstitucionales". Sin embargo, esta denominación es 
considerada como sinónimo de "grupos de presión", "grupos interés" y de lobistas. Así mismo, incluye a los consultores profesionales, los bufetes de abogados, a quienes trabajan en relación de dependencia para una corporación (in house loobists), a las asociaciones profesionales, a las uniones comerciales, a las organizaciones no gubernamentales (ONGs), a las organizaciones académicas y a las religiosas $v$. (European Comission for Democracy Through Law, 2013).

En la Ley N. 28024 de Perú se denomina a los actores que realizan lobbying como "gestores de intereses" y su artículo 7 prevé la siguiente definición ${ }^{20}$ :

La persona natural o jurídica, nacional o extranjera, debidamente inscrita en el registro correspondiente, que desarrolle actos de gestión de sus propios intereses o de terceros, en relación con las decisiones públicas adoptadas por los funcionarios públicos comprendidos en el artículo 5 de la presente ley.

La Ley clasifica a los "gestores de intereses" en dos categorías. En el primero están los que se dedican a esta actividad en función de intereses propios; los asociados, socios, accionistas o representantes legales que actúen con poder suficiente a nombre de personas jurídicas; y los organismos gremiales, empresariales, laborales y profesionales sin fines de lucro. Al segundo grupo se lo denomina "gestores de intereses profesionales" e incluye a quienes realizan esta actividad en representación de terceros a cambio de una prestación económica. No obstante, ambos grupos están sujetos a las mismas regulaciones.

La Ley chilena sobre la materia ${ }^{21}$ sigue una lógica similar a la de la legislación peruana en cuanto a los actores privados que se dedican al lobbying. El numeral 5 del artículo 1 dispone que un lobista es: "la persona natural o jurídica, chilena o extranjera, remunerada, que realiza lobby. Si ello no media remuneración se denominará gestor de intereses particulares, sean estos individuales o colectivos." Esta norma distingue a los lobistas de los gestores de intereses en función de si se trata de una actividad remunerada o no, pero, al igual que en Perú, no existe diferenciación en cuanto a las reglas que los rigen.

20 Perú. (2003, julio 11). Ley N. 28024 que regula la gestión de intereses en la administración pública.

21 Chile. (2014). Ley 20730 que regula el lobby y las gestiones que representen intereses particulares ante las autoridades y funcionarios. Id Norma 1060115. 
En el proyecto de ley sobre lobbying, que se discute en el legislativo colombiano, se define a los "cabilderos" como: "cualquier persona natural o jurídica, nacional o extranjera, que desarrolle actividades de cabildeo ante las autoridades" ${ }^{22}$. En este mismo sentido la Propuesta Normativa ${ }^{23}$ que se debate en argentina prevé que un "gestor de intereses" es: "toda persona que ejerza de forma habitual u ocasional la gestión de intereses". Estas definiciones reflejan que, si bien en la legislación peruana y chilena se hace cierta diferenciación entre los actores que realizan lobbying a cambio de una remuneración y quienes no, la regulación es la misma para todos. El dejar de lado las asimetrías entre los distintos sectores de la sociedad civil ha sido una de las críticas que se ha formulado a estos mecanismos participativos.

Por ejemplo, el expresidente de Estados Unidos, Barack Obama manifestaba lo siguiente:

Nunca me he sentido del todo cómodo con el término "intereses especiales", que junta bajo el mismo apelativo a ExxonMobil y a los albañiles, al lobby farmacéutico y a los padres de niños con necesidades especiales. La mayoría de los científicos políticos probablemente no estarían de acuerdo conmigo, pero para mí no es lo mismo un grupo de presión empresarial cuya fuerza se basa exclusivamente en el dinero, que un grupo de individuos que sostienen las mismas ideas -ya sean trabajadores textiles, aficionados a las armas, veteranos o familiares de granjeros- y que se unen para defender sus intereses. Creo que no son lo mismo aquellos que usan su poder económico para magnificar su influencia política mucho más allá de lo que justificaría su número, que aquellos que simplemente tratan de unir la fuerza de sus votos para conseguir convencer a sus representantes. Los primeros atacan la idea misma de la democracia. Los segundos son su esencia (Córdova, 2017, pág. 72).

En esta misma línea, partiendo desde concepciones teóricas de la sociedad civil como la de Gramsci, se explica que en estos procesos no todos los actores participan en igualdad de condiciones. Por lo tanto,

22 Colombia, Comisión Primera Cámara de Representantes. (2017). Ponencia para primer debaten en la Comisión Primera de la Cámara de Representantes de Proyecto de Ley No.296 de 2017 Cámara, 096 de 2016 de Senado "Por el cual se regula el ejericio de cabildeo y se dictan otras disposiciones."

23 Argentina, Jefatura de Gabinete de Ministros. (2017). Proyecto de Ley Gestión de Intereses. Mensaje No. 34 . 
establecer las mismas reglas para todos beneficiaría a los intereses de quienes están en posición de ventaja por condiciones materiales que superan el ámbito formal. Para el filósofo italiano, el Estado lo conforman la sociedad política y la sociedad civil. La sociedad política es la esfera donde se garantiza el statu quo determinado por las relaciones económicas mediante la coerción (legislación). En contraste, en la sociedad civil, mediante el consenso y la persuasión, se construye un relato que aglutina a los ciudadanos en distintas formas de organización v.(Kumar, 1993).

Según Gramsci, la hegemonía cultural es la aceptación mayoritaria de un relato que avala una visión de la realidad que denomina ideología. Todo este conjunto de interacciones se las identifica como un bloque histórico $v$.(Puentes y Suárez, 2016). En los momentos de estabilidad, el bloque histórico será congruente entre sí. En consecuencia, los intereses que primen en la sociedad civil serán los de los grupos dominantes en lo económico.

\subsection{El lobbying como mecanismo participativo y el principio democrático}

Las relaciones económicas estructurales no solo inciden en el ámbito de la sociedad civil, sino en todos los demás espacios sociales. Por lo tanto, estas no influyen únicamente en los mecanismos participativos, se manifiestan en todas las dimensiones de la democracia. Sin embargo, mediante la legislación se han desarrollado instrumentos para disminuir la relevancia de las asimetrías económicas en los procesos de toma de decisiones públicas, en especial mediante los procesos democráticos representativos. Por este motivo, cuando la falta de transparencia permite que el lobbying no se someta a estos controles, la tensión entre el principio democrático y la desigualdad estructural entre los actores sociales resulta más evidente. Esto debilita la legitimidad de esta práctica. La democracia representativa supone la elección de los representantes de los organismos del Estado mediante el ejercicio del derecho al sufragio de todos los ciudadanos. Aunque otros factores como el manejo de la opinión pública y la financiación de los partidos políticos causan que los intereses de los sectores con más recursos económicos tengan mayores probabilidades de imponerse, estos procesos al menos garantizan que todos los votos tengan el mismo valor. Esto quiere decir que formalmente el estatus de ciudadanía es suficiente para ejercer este derecho en condiciones de igualdad. 
El estatus de ciudadanía es suficiente para que las personas sean titulares de derechos. En contraposición, cuando los actores de los procesos democráticos son los "grupos presión" no basta con ser ciudadano para intervenir en estos. Estas organizaciones se crean para defender intereses concretos. Por lo tanto, los puntos de vista que avalen no serán los de todos los individuos, sino solo los de aquellos que tenga ciertas posiciones, cualidades o recursos afines a sus causas $v$. (Pacheco, 2012).

En consecuencia, la participación mediante "grupos de presión" implica el riesgo que existan posiciones ciudadanas que queden anuladas por no ser consideradas relevantes por ningún de ellos o que las opiniones de colectivos que representan ciertos sectores sean excluidas de los procesos de toma de decisiones. En estos casos, la intervención en la deliberación pública ya no dependería solo del estatus de ciudadanía sino de otros factores como tener ciertos conocimientos o recursos económicos.

Otro de los riesgos de la participación mediante "grupos de presión" es la anulación del conflicto político v.(Pacheco, 2012). La intervención en este tipo de procesos muchas veces está sujeta a determinados requisitos que aparentemente son neutros o técnicos. Sin embargo, esta predeterminación no toma en cuenta que estos saberes generalmente responden a una posición ideológica, lo que implica que los puntos de vista contrarios quedan de plano descartados del debate público. Por lo general, la imposición de estas visiones como única opción viable deviene de un proceso de construcción hegemónica, por lo que representa únicamente a los sectores dominantes en lo económico. Si bien es cierto los instrumentes regulatorios que pretenden transparentar el lobbying no corrigen las asimetrías entre los actores de la sociedad civil, como bien lo señalan sus críticos; al menos permiten que los electores tengan la posibilidad de conocer con quienes se reúnen sus representantes políticos y saquen sus propias conclusiones respecto a quien realmente beneficia estas actuaciones.

Por lo tanto, esto es un mecanismo para evitar que la influencia de los "grupos de presión" sea una forma de evadir el control democrático de los ciudadanos. Esto, sin solucionar totalmente los problemas de legitimidad que presenta esta actividad, es un avance en comparación con la existencia de prácticas opacas de influencia, ante la ausencia de un marco normativo que las regle. 


\section{MECANISMOS PARTICIPATIVOS EN EL ORDENAMIENTO JURÍDICO ECUATORIANO}

El fortalecimiento de los mecanismos participativos desde la sociedad civil fue uno de los ejes del proceso constituyente del 2008. El artículo 95 de la Carta Magna dispone la construcción permanente del poder ciudadano. Este proceso consiste en la participación protagónica de la ciudadanía, de forma individual o colectiva, en los asuntos públicos y en el control popular de las instituciones del Estado y la sociedad ${ }^{24}$. En este mismo sentido, el artículo 96 reconoce a todas las formas de organización de la sociedad como expresión de la soberanía popular para incidir en los procesos de toma de decisiones públicas y ejercer control social.

El artículo 100 de la Norma Fundamental ordena que en todos los niveles de gobierno se conformen instancias de participación, que tengan incidencia en el manejo de planes y políticas públicas, con representantes de la sociedad civil; la elaboración de presupuestos participativos; la construcción de mecanismos para garantizar la transparencia y la rendición de cuentas; y promover la formación ciudadana y los procesos de comunicación.

Estos preceptos constitucionales son desarrollados por la Ley Orgánica de Participación Ciudadana (LOPC) ${ }^{25}$. Este cuerpo normativo prevé mecanismos institucionales que tienen la finalidad de materializar el principio de poder ciudadano dispuesto por la Carta Magna. Los actores de la sociedad civil son denominados organizaciones sociales y el artículo 30 las reconoce como una expresión de la soberanía popular que aporta a la defensa de derechos individuales y colectivos; a la gestión y resolución de problemas y conflictos; al fomento de la solidaridad, la democracia y el buenvivir; y que inciden en las decisiones públicas. La LOPC prevé varias instancias para incluir a las organizaciones sociales en los procesos de toma de decisiones. Una de estas es la Asamblea Ciudadana Plurinacional (ACP), prevista en el artículo 48 y subsiguientes de esta ley. La ACP es un organismo consultivo del Consejo Nacional de Planificación ${ }^{26}$ que lo conforman delegados de las asam-

24 Ecuador. (2008).Constitución de la República. R.O 449.

25 Ecuador. (2011).Ley Orgánica de Participación Ciudadana. R.O Suplemento 175.

26 El Consejo Nacional de Planificación es un organismo creado por el artículo 279 de la Constitución que integra a los distintos niveles de gobierno, lo preside el Presidente de la República y tiene como finalidad orientar las políticas de planificación y aprobar el Plan Nacional de Desarrollo. 
bleas locales de participación, de cada consejo ciudadano sectorial y de las organizaciones de la sociedad civil.

A su vez, las asambleas locales de participación, según el artículo 56 de esta Ley, son organismos que pueden ser conformados por la ciudadanía en los distintos niveles de gobierno para fortalecer sus capacidades de interlocución con las autoridades e influir en la gestión de lo público. Por su parte, los consejos ciudadanos sectoriales, previstos en el artículo 52, son redes de participación de la sociedad civil de alcance nacional que se articulan a los ministerios, por lo que deben ser promovidas desde la función ejecutiva.

Otra de las instancias de participación de las organizaciones de la sociedad civil son los consejos nacionales para la igualdad que deben conformarse paritariamente por representantes del Estado y la sociedad civil. Estos organismos tienen como finalidad incidir en la formulación de las políticas públicas relativas a grupos sociales específicos.

El artículo 72 de la LOPC define a los mecanismos de participación ciudadana en la gestión pública como "instrumentos con los que cuenta la ciudadanía de forma individual o colectiva para participar en todos los niveles de gobierno". Entre estos se encuentran las audiencias públicas que son instancias en las que una autoridad, por su propia voluntad o por pedido de los ciudadanos, atiende sus peticiones y recoge criterios para fundamentar sus decisiones.

Otro de los mecanismos participativos relevantes es la consulta previa, libre e informada a las comunas, pueblos y nacionalidades indígenas, pueblos afroecuatorianos y montubios en todo proceso decisorio que les afecte. Este instrumento se hace extensivo en materia ambiental a toda comunidad. Los resultados de estas deliberaciones deben ser valoradas en la fundamentación de la decisión final.

Las veedurías, los observatorios y consejos consultivos también son mecanismos dispuestos por LOPC para garantizar la participación ciudadana en los distintos niveles de gobierno. Así mismo, a nivel local las instancias de participación son diversas. La Ley prevé la implementación de consejos locales de planificación, presupuestos participativos, cabildos populares, la inclusión de una "silla vacía" en los consejos de los gobiernos autónomos descentralizados, entre otros. Pese a la abundancia de los instrumentos de participación de la sociedad civil previsto en la LOPC, no todos los contactos entre 
las autoridades y estos sectores se dan mediante estos mecanismos institucionales. Por lo tanto, persiste una zona gris que este cuerpo normativo no alcanza a transparentar.

En el ámbito parlamentario tampoco existen los instrumentos suficientes para restarle opacidad a la influencia de los "grupos de presión” en los asambleístas y los demás funcionarios legislativos. En materia de transparencia, la Ley Orgánica de la Función Legislativa $(\mathrm{LOFL})^{27}$ se limita a disponer la publicidad de las sesiones del pleno, la posibilidad de dar seguimiento a las sesiones de las comisiones y la publicación de toda la información y documentación de la Asamblea Nacional en su portal de internet. Respecto a la participación ciudadana, la LOFL señala que se la promoverá mediante mecanismos como la recepción de sugerencias, foros de consulta y mesas itinerantes. Estos aportes deberán procesarse mediante las comisiones especializadas correspondientes. De igual forma, deja la puerta abierta al establecimiento de instrumentos que acerquen a la sociedad civil a los legisladores y a los organismos de la Asamblea Nacional.

La Ley Orgánica de Transparencia y Acceso a la Información tampoco contiene instrumentos que aporten a transparentar de la influencia de los actores de la sociedad civil en los cargos públicos. El artículo 5 de este cuerpo normativo prevé una definición amplia de información pública. No obstante, el artículo 7, que regula la información mínima que están obligados a publicar todos los sujetos regulados, no incluye ningún dato relacionado con la "gestión de intereses"

Así mismo, el artículo 14 de la Ley, que dispone deberes específicos en este ámbito para el parlamento, únicamente incluye la divulgación de "los textos completos de todos los proyectos de Ley que sean presentados al Congreso Nacional, señalando la Comisión Especializada Permanente asignada, la fecha de presentación, el código; y el nombre del auspiciante del proyecto" y "una lista de proyectos de ley que hubieren sido asignados a cada Comisión Especializada Permanente".

La identificación del "auspiciante del proyecto" únicamente revelaría datos sobre la actividad de los "grupos de presión" en los procesos de iniciativa legislativa popular, ya que cuando la propuesta la

27 Ecuador. (2007).Ley Orgánica de la Función Legislativa. R.O Suplemento 642.

28 Ecuador. (2004). Ley Orgánica de Transparencia y Acceso a la Información Pública. Registro Oficial 337. 
realiza el Presidente de la República, un grupo de legisladores u otro representante de los organismos estales serán ellos quienes consten formalmente como auspiciantes, independientemente de los actores de la sociedad civil que les motivaron a presentarla.

En conclusión, el ordenamiento jurídico ecuatoriano no dispone de los instrumentos suficientes para la transparentar las actividades que de facto realizan los "grupos de presión" para influenciar en los procesos de toma de decisiones públicas, por fuera de los mecanismos institucionales formales. Esto resulta más evidente, si se contrasta la legislación ecuatoriana con los mecanismos regulatorios con los que cuentas otros países de Sudamérica.

\section{MECANISMOS PARA REGULAR EN LOBBYING EN LOS PAÍSES DE SUDAMÉRICA}

Actualmente, cuatro países de Sudamérica ya cuenta con normas jurídicas para regular el lobbying. Chile y Perú disponen de leyes específicas sobre la materia. En Argentina existe un decreto que regula la "gestión de intereses" en el poder ejecutivo y el parlamento se encuentra tramitando un proyecto de ley. El ordenamiento jurídico colombiano contiene una disposición constitucional que ordena legislar sobre "cabildeo", un artículo de la Ley $1474^{29}$ autoriza a las autoridades competentes a indagar sobre este tipo de actividades, una resolución de la Cámara de Representantes crea un registro de cabilderos para ese organismo y una propuesta normativa está en trámite. A estos cuatro países se suma Brasil donde el legislativo federal se encuentra debatiendo desde el año 2007 un proyecto de ley al respecto.

Las distintas normas jurídicas y proyectos de ley de estos países cuentan con varios instrumentos que aportan a la transparencia del lobbying. En este mismo sentido, estos mecanismos contribuyen a que la ciudadanía conozca los intereses de los "grupos de presión" que influyen en sus representantes políticos y en los procesos de toma de decisiones públicas. Las herramientas regulatorias más destacadas son los registros que contienen información relacionada con la "gestión de intereses".

29 Colombia. (2011). Ley 1474 de 2011. Diario Oficial No. 48128. 


\subsection{Alcance subjetivo de la regulación del lobbying}

Antes de detallar cómo funcionan y en qué consisten estos registros resulta interesante revisar el alcance subjetivo de estas normas. En los ordenamientos jurídicos de los países analizados, la tendencia es a ampliar los funcionarios públicos obligados. Cómo se detalla a continuación el ámbito de aplicación de las leyes chilena y peruana son todos los poderes del Estado. En Argentina y Colombia, actualmente, la regulación solo cubre al ejecutivo y al legislativo, respectivamente; pero las propuestas normativas que se están tramitando pretenden ampliarla a los demás poderes. El Proyecto de Ley brasileño también va en esta línea.

En Argentina, el artículo 2 del Decreto 1172/2003 define que los funcionarios obligados son el Presidente de la Nación, el Vicepresidente, el Jefe de Gabinete de Ministros, los ministros, los secretarios y subsecretarios, los interventores federales y las autoridades superiores de los organismos, entidades, empresas, sociedades y dependencias que funciones bajo la jurisdicción del poder ejecutivo nacional.

Así mismo, la norma prevé que los demás funcionarios públicos, que incidan en los procesos de toma de decisiones y no se encuentren entre los mencionados expresamente por el artículo 2 del Decreto $1172 / 2003$, deberán notificar al jerárquico superior obligado de todas las actividades de "gestión de intereses" en la que participen para que este proceda a publicar en su registro. El plazo máximo para reportar es de cinco días. Esta disposición es importante destacar como un mecanismo para evitar que los sujetos destinatarios de la regulación evadan estos controles mediante el envío de emisarios a las negociaciones con los "grupos de presión".

A diferencia del Decreto 1172/ 2003, el proyecto de ley que se debate en el parlamento argentino pretende ampliar el espectro de regulación a todos los organismos del Estado y no solo al poder ejecutivo. En consecuencia, los sujetos obligados son los detallados en el Gráfico A. 


\section{Gráfico A: funcionarios Públicos obligados por el Proyecto de Ley Gestión de Intereses}

\begin{tabular}{|c|c|c|}
\hline Poder Ejecutivo & Poder Legislativo & Poder Judicial \\
\hline $\begin{array}{l}\text { Presidente, Vicepresidente } \\
\text { de la nación; el Jefe de Gabi- } \\
\text { nete; los ministros y secreta- } \\
\text { rios con rango ministerial; } \\
\text { los secretarios, subsecreta- } \\
\text { rios y directores generales; } \\
\text { los asesores directos de } \\
\text { todos estos funcionarios. }\end{array}$ & $\begin{array}{c}\text { Los diputados, senadores } \\
\text { y sus asesores. }\end{array}$ & Los magistrados. \\
\hline $\begin{array}{l}\text { Los interventores federales; } \\
\text { los funcionarios superiores } \\
\text { de los entes autárquicos } \\
\text { y descentralizados; las } \\
\text { autoridades superiores de } \\
\text { los entes reguladores y los } \\
\text { demás organismos que inte- } \\
\text { gran los sistemas de control } \\
\text { del sector público. }\end{array}$ & $\begin{array}{c}\text { Los funcionarios de } \\
\text { ambas cámaras con rango } \\
\text { no inferior a director o } \\
\text { equivalente. }\end{array}$ & $\begin{array}{c}\text { Los secretarios y demás } \\
\text { funcionarios con rango } \\
\text { equivalente o superior }\end{array}$ \\
\hline $\begin{array}{l}\text { Los representantes del } \\
\text { Estado y gerentes de las } \\
\text { empresas estatales o con } \\
\text { participación accionaria } \\
\text { pública; los miembros de } \\
\text { los organismos jurisdic- } \\
\text { cionales administrativos }\end{array}$ & $\begin{array}{l}\text { El presidente y los } \\
\text { auditores generales de la } \\
\text { Auditoría General de la } \\
\text { Nación; el Defensor del } \\
\text { Pueblo y sus adjuntos; el } \\
\text { Procurados Penitenciario }\end{array}$ & $\begin{array}{l}\text { Los miembros del Consejo } \\
\text { de la Magistratura, el Ju- } \\
\text { rado de Enjuiciamiento de } \\
\text { Magistrados de la Nación, } \\
\text { del Tribunal de Enjuicia- } \\
\text { miento del Ministerio } \\
\text { Público de la Defensa y de } \\
\text { Tribunal de Enjuiciamien- } \\
\text { to del Ministerio Público } \\
\text { Fiscal de la Nación }\end{array}$ \\
\hline
\end{tabular}


Los rectores, decanos y se-

cretarios de las universida-

des nacionales; los emba-

jadores o funcionarios del

servicio exterior con ese

rango, el Síndico General

de la Nación y los Síndicos

Generales Adjuntos

Elaboración: Propia

En comparación con el Decreto 1172/ 2003, este proyecto de ley amplía el ámbito de aplicación subjetivo de los deberes jurídicos dispuestos en la norma, incluso dentro del poder ejecutivo. Sin embargo, en contraposición con ese decreto, la Propuesta Normativa no contempla el deber de notificar al jerárquico superior de todas las actividades de "gestión de intereses" en la que participen los funcionarios que no se encuentran definidos como sujetos obligados $v$. (Dates y Sama, 2017)..

Por su parte, el ámbito de aplicación de la Resolución N. MD-2348 de la Cámara de Representantes colombiana alcanza únicamente a los lobistas cuando se reúnen con los funcionarios públicos que laboran en este organismo. Sin embargo, el proyecto de ley que pretende regular el cabildeo abarca a las autoridades a las que se detalla en el Gráfico B.

30 Colombia. (2011). Resolución MD-2348 de 2011. Cámara de Representantes. Tomado de http://www.camara.gov.co/participacion-ciudadana/registro-publico-de-cabilderos. Consultado 4 de abril del 2018. 
Gráfico B: autoridades reguladas por el Proyecto de Ley No.296

\begin{tabular}{|c|c|c|c|}
\hline $\begin{array}{l}\text { Rama Ejecutiva y } \\
\text { Fuerzas Armadas }\end{array}$ & Rama Legislativa & Rama Judicial & $\begin{array}{l}\text { Nivel Territorial } \\
\text { y otros }\end{array}$ \\
\hline $\begin{array}{l}\text { Presidente de } \\
\text { la República, el } \\
\text { vicepresidente, } \\
\text { ministros, vicemi- } \\
\text { nistros, directores } \\
\text { de departamentos } \\
\text { administrativos. }\end{array}$ & Congresistas. & $\begin{array}{l}\text { Fiscal General de } \\
\text { la Nación. }\end{array}$ & $\begin{array}{l}\text { Alcaldes munici- } \\
\text { pales, alcaldes de } \\
\text { distrito y el alcalde } \\
\text { Mayor de la ciudad } \\
\text { de Bogotá. }\end{array}$ \\
\hline $\begin{array}{l}\text { Superintendentes, } \\
\text { los directores de } \\
\text { unidades adminis- } \\
\text { trativas, altos comi- } \\
\text { sionados, ministros } \\
\text { consejeros, secreta- } \\
\text { rios y directores de } \\
\text { la Presidencia de la } \\
\text { República. }\end{array}$ & $\begin{array}{l}\text { Directores Ad- } \\
\text { ministrativos, } \\
\text { secretarios y } \\
\text { subsecretarios de } \\
\text { las comisiones. }\end{array}$ & $\begin{array}{l}\text { Magistrados de la } \\
\text { Sala Administra- } \\
\text { tiva del Consejo } \\
\text { Superior de la Judi- } \\
\text { catura, el Director } \\
\text { Ejecutivo de la } \\
\text { Rama Judicial. }\end{array}$ & $\begin{array}{c}\text { Gobernadores, } \\
\text { gerentes, presiden- } \\
\text { tes y directores } \\
\text { de las entidades } \\
\text { descentralizadas } \\
\text { por servicios. }\end{array}$ \\
\hline $\begin{array}{c}\text { Secretarios } \\
\text { privados, secre- } \\
\text { tarios senerales, } \\
\text { superintendentes } \\
\text { delegados, directo- } \\
\text { res y asesores. }\end{array}$ & & $\begin{array}{l}\text { Magistrados de la } \\
\text { Corte Constitu- } \\
\text { cional, de la Corte } \\
\text { Suprema de Justi- } \\
\text { cia, del Consejo de } \\
\text { Estado y del conse- } \\
\text { jo superior de la } \\
\text { judicatura sala } \\
\text { disciplinaria. }^{33}\end{array}$ & $\begin{array}{l}\text { Diputados, conce- } \\
\text { jales y miembros } \\
\text { de las Unidades de } \\
\text { Apoyo Normativo. }\end{array}$ \\
\hline
\end{tabular}

31 Órganos de control, organismos autónomos e independientes.

32 Cooperativas, fundaciones, corporaciones y asociaciones que se creen y organicen por el Estado o con su participación mayoritaria.

33 Los magistrados de las Salas Administrativas de los Consejos Seccionales de la Judicatura también son sujetos de esta regulación, pero, únicamente, en lo que tiene que ver con el ejercicio de la función administrativa que les compete, al igual que los magistrados de los Tribunales. 


\begin{tabular}{|c|c|c|}
\hline $\begin{array}{l}\text { Gerentes del sec- } \\
\text { tor público empre- } \\
\text { sarial. Embajado- } \\
\text { res, y Cónsules. }\end{array}$ & $\begin{array}{l}\text { Los asesores en el } \\
\text { ejercicio de estas } \\
\text { los funcionarios } \\
\text { mencionados ante- } \\
\text { riormente. }\end{array}$ & $\begin{array}{l}\text { Secretarios priva- } \\
\text { dos, secretarios ge- } \\
\text { nerales, subsecre- } \\
\text { tarios y asesores. }\end{array}$ \\
\hline $\begin{array}{c}\text { Gerentes, presi- } \\
\text { dentes o directores } \\
\text { de las entidades } \\
\text { descentralizadas } \\
\text { por servicios y } \\
\text { los miembros de } \\
\text { las Comisiones de } \\
\text { Regulación. }\end{array}$ & & $\begin{array}{c}\text { El Procurador } \\
\text { General de la } \\
\text { Nación, Defensor } \\
\text { del Pueblo, el } \\
\text { Contralor General, } \\
\text { el Registrador Na- } \\
\text { cional del Estado } \\
\text { Civil. }\end{array}$ \\
\hline \multirow[t]{3}{*}{$\begin{array}{l}\text { Director Gene- } \\
\text { ral de la Policía } \\
\text { Nacional, los Co- } \\
\text { mandantes de las } \\
\text { tres ramas de las } \\
\text { FF.AA y los demás } \\
\text { miembros de la } \\
\text { fuerza pública } \\
\text { encargados de las } \\
\text { adquisiciones. }\end{array}$} & & $\begin{array}{c}\text { Magistrados del } \\
\text { Consejo Nacional } \\
\text { Electoral. }\end{array}$ \\
\hline & & $\begin{array}{l}\text { Miembros de la } \\
\text { Junta Directiva } \\
\text { del Banco de la } \\
\text { República. }\end{array}$ \\
\hline & & $\begin{array}{l}\text { Rectores de las } \\
\text { Universidades Pú- } \\
\text { blicas, -Directivos } \\
\text { de las Corporacio- } \\
\text { nes Autónomas } \\
\text { Regionales. -Co- } \\
\text { misionados de la } \\
\text { Comisión Nacional } \\
\text { del Servicio Civil. }\end{array}$ \\
\hline
\end{tabular}

Elaboración: Propia 
Los artículos 3 y 4 de la La Ley 20730 chilena explicitan los sujetos pasivos regulados como lo detalla el Gráfico C.

\section{Gráfico C: funcionarios Públicos Obligados por Ley 20730}

\begin{tabular}{|c|c|c|c|c|}
\hline $\begin{array}{c}\text { Poder } \\
\text { Ejecutivo }\end{array}$ & $\begin{array}{l}\text { Congreso } \\
\text { Nacional }\end{array}$ & Poder Judicial & $\begin{array}{l}\text { Administra- } \\
\text { ción Local o } \\
\text { Comunal }\end{array}$ & Otros \\
\hline $\begin{array}{l}\text { •Ministros, } \\
\text { subsecreta- } \\
\text { rios, jefes de } \\
\text { servicios, } \\
\text { directores } \\
\text { regionales, } \\
\text { delegados } \\
\text { presidenciales } \\
\text { regionales y } \\
\text { provinciales. } \\
\text { •Gobernado- } \\
\text { res regionales, } \\
\text { los secretarios } \\
\text { regionales } \\
\text { ministeriales. } \\
\text { •Embajadores. } \\
\text { •Jefes de gabi- } \\
\text { nete }{ }^{35} \text {. }\end{array}$ & $\begin{array}{l}\text {-Diputados y } \\
\text { senadores. } \\
\text { •Secretario } \\
\text { general y pro- } \\
\text { secretario de } \\
\text { la Cámara de } \\
\text { Diputados y el } \\
\text { Senado. } \\
\text {-Asesores } \\
\text { legislativos } \\
\text { que indique } \\
\text { anualmente } \\
\text { cada parla- } \\
\text { mentario. }\end{array}$ & $\begin{array}{l}\text { •Fiscal na- } \\
\text { cional y los } \\
\text { regionales. } \\
\text { •Director de la } \\
\text { Corporación } \\
\text { Administra- } \\
\text { tiva del Poder } \\
\text { Judicial. }\end{array}$ & $\begin{array}{l}\text { •Alcaldes } \\
\text { •Los miem- } \\
\text { bros de los } \\
\text { organismos } \\
\text { representa- } \\
\text { tivos de cada } \\
\text { uno de los } \\
\text { niveles de } \\
\text { gobierno y sus } \\
\text { secretarios } \\
\text { ejecutivos. } \\
\text {-Directores } \\
\text { de obras y } \\
\text { secretarios } \\
\text { municipales. }\end{array}$ & $\begin{array}{l}\text { •Contralor y } \\
\text { Subcontralor } \\
\text { General. } \\
\text { •Presidente, } \\
\text { vicepresidente } \\
\text { y consejeros } \\
\text { del Banco } \\
\text { Central. } \\
\text {-Alto mando } \\
\text { de las fuerzas } \\
\text { de seguridad } \\
\text { y los encar- } \\
\text { gados de los } \\
\text { procesos de } \\
\text { contratación. } \\
\text { •Miembros de } \\
\text { consejos Ley. }{ }^{36}\end{array}$ \\
\hline
\end{tabular}

34 La ley incluye en general a: "los servidores públicos del nivel directivo y asesor de los órganos autónomos e independientes. También están cobijados por la presente ley sus Secretarios Privados, Secretarios Generales, Delegados, Directores y Asesores y Representantes en cualquier nivel territorial".

35 El artículo 3 de la Ley 20730 amplía el ámbito de aplicación A: "las personas que, en razón de su función o cargo, tengan atribuciones decisorias relevantes o influyan decisivamente en quienes tengan dichas atribuciones y reciban por ello regularmente una remuneración."

36 El artículo 4 numeral 7 de la Ley 20730 incluye los siguientes: "Consejo de Defensa del Estado, del Consejo Directivo del Servicio Electoral, del Consejo para la Transparencia, del Consejo de Alta Dirección Pública, del Consejo Nacional de Televisión, del Instituto Nacional de Derechos Humanos. 
En las instituciones u organismos en los que laboran los sujetos pasivos señalados explícitamente por esta ley, se pueden ampliar los funcionarios obligados mediante resolución de la entidad competente en cada una de ellas. Esta atribución también es aplicable para el Poder Judicial, el Tribunal Constitucional y la Justicia Electoral. La lista de los cargos públicos a los que se les haga extensiva esta obligación deberá ser publicada de manera permanente en las páginas de internet institucionales. Así mismo, cualquier ciudadano puede solicitar motivadamente que se incluya a alguna autoridad. El ente competente, según el caso, deberá resolver la petición en el término máximo de diez días hábiles. La respuesta que se dé será de única instancia, por lo que deberá ser adecuadamente justificada. En este mismo sentido, la Ley 28024 de Perú regula a los funcionarios públicos que detalla el Gráfico D.

Gráfico D: funcionarios públicos obligados por la Ley N. 28024 ${ }^{37}$

\begin{tabular}{|c|c|c|c|}
\hline Poder Ejecutivo & Poder Legislativo & $\begin{array}{c}\text { Administración } \\
\text { Local }\end{array}$ & $\begin{array}{l}\text { Sector Público } \\
\text { Empresarial }\end{array}$ \\
\hline $\begin{array}{l}\text {-Presidente de la } \\
\text { República. } \\
\text { •Primer y segundo } \\
\text { vicepresidente. } \\
\text { •Ministros, vice- } \\
\text { ministros, secre- } \\
\text { tarios generales, } \\
\text { directores nacio- } \\
\text { nales y generales. } \\
\text {-Titulares de los } \\
\text { pliegos presupues- } \\
\text { tarios de entidades } \\
\text { de la administra- } \\
\text { ción pública. }\end{array}$ & -Congresistas. & $\begin{array}{l}\text { •Perfectos, subpre- } \\
\text { fectos, consejeros, } \\
\text { asesores y demás } \\
\text { con rango funcio- } \\
\text { nal equivalente. } \\
\text { •Consejeros de los } \\
\text { órganos represen- } \\
\text { tativos regionales, } \\
\text { su presidente y el } \\
\text { vicepresidente, } \\
\text { cuando lo subrogue. } \\
\text { •Alcaldes, regido- } \\
\text { res y directores de } \\
\text { las municipalida- } \\
\text { des provinciales y } \\
\text { distritales. }\end{array}$ & $\begin{array}{l}\text { •Presidentes, ge- } \\
\text { rentes y miembros } \\
\text { del directorio. }\end{array}$ \\
\hline
\end{tabular}

37 El literal k) del artículo 5 de la Ley prevé lo siguiente: "En general los funcionarios con capacidad de decisión pública, de acuerdo con lo que establezca el reglamento de la presente Ley". Por lo tanto, se deduce que esta lista no es taxativa y puede ampliarse mediante reglamento. 


\subsection{Registros de reuniones}

Este mecanismo regulatorio se basa en la obligación de los cargos públicos de registrar y publicar todo tipo de contacto o reuniones con actores privados en el marco del ejercicio de sus funciones. Este modelo es por el que se ha optado en Argentina tanto en la normativa infralegal vigente como en el proyecto de ley que se encuentra en trámite.

El Decreto 1172/ 2003 obliga a los altos cargos del poder ejecutivo federal a registrar y publicar toda audiencia que tenga como finalidad la "gestión de intereses". Estos registros deben contener las solicitudes de audiencia; los datos del solicitante; los intereses que invocan; las participantes de la audiencia; el lugar, fecha y hora de la reunión; una síntesis del contenido de la reunión; y constancias que la audiencia fue efectivamente realizada. Estos datos son de carácter público, por lo que su libre acceso debe garantizarse mediante la actualización y difusión diaria a través de las páginas de internet institucionales.

Así mismo, toda persona natural o jurídica está legitimada para solicitar estos datos por vía administrativa o judicial. La única excepción a la publicidad es aquella información que haya sido declarada, mediante decreto ejecutivo o ley, como reservada o secreta. El incumplimiento a las disposiciones previstas en el Decreto 1172/2003 es considerado una falta grave, lo que es una causal del juicio político.

En este mismo sentido, el proyecto de ley que se debate en el parlamento argentino dispone la creación de un registro de las audiencias de "gestión de intereses" que deberá contener los datos del lugar donde se realizó; la fecha y hora; nombre de los solicitantes y los asistentes; nombre o razón social de la persona cuyos intereses se gestionaron, si se trata de intereses colectivos o difusos, hacerlo constar; y una síntesis de contenido de la reunión. Este registro debe estar disponible para el público en las páginas de internet y debe ser actualizado de forma constante por los sujetos obligados.

\subsection{Registros de Lobistas}

Este mecanismo regulatorio consiste en un registro en el que deben apuntarse todos los lobistas antes de solicitar una reunión con los funcionarios públicos. En ciertos casos, la inscripción incluye la generación de una credencial que permite el acceso a las instalaciones de las 
dependencias públicas. Este modelo es el que se aplica actualmente en la Cámara de Representantes de Colombia y en el Proyecto de Ley brasileño. La ventaja de los registros de agenda sobre los de lobistas es que cubren también aquellas reuniones con sujetos que no necesariamente realizan permanente lobbying, pero que pueden ser muy relevantes para una decisión específica.

En el modelo actualmente vigente en la Cámara de Representantes de Colombia, las personas naturales o jurídicas que pretendan registrarse deben presentar la solicitud de inscripción o la carta de presentación cuando actúe como representante de un tercero; su nombre completo con los datos de identificación y ubicación (copia de documento de identidad); en caso de formar parte de una firma especializada en lobbying se debe acreditar la personalidad jurídica de la entidad y, de todas formas, inscribirse también como individuo.

Este trámite es gratuito y la respuesta a la solicitud debe darse en un plazo máximo de tres días. La negación de inscripción debe fundamentarse mediante acto administrativo, con la finalidad que el interesado tenga a su disposición las vías de impugnación previstas para este tipo de actuaciones. Cuando el registro se lleve a cabo, la Cámara de Representantes emitirá automáticamente una credencial. La inscripción en el Registro de Cabilderos faculta a los lobistas a establecer contactos con los miembros de la Cámara de Representantes, esto incluye el acceso permanente a las instalaciones donde funciona este organismo. En contraste, los ciudadanos que no se dedican a esta actividad de forma permanente deben solicitar un permiso previo para entrar en la oficina que visitarán. Sin embargo, esta regulación no debe limitar la posibilidad de dirigir observaciones a las autoridades públicas sobre los actos jurídicos que se encuentran tramitando, ni al ejercicio del derecho de petición.

Por su parte, el sistema regulatorio, que se debate en Brasil, abarca a los tres poderes del Estado Federal y consiste en un registro en el que deberán constar los lobistas que las personas naturales o jurídicas acrediten como sus representantes. Cada una de ellas podría nombrar un titular y un suplente. Este mecanismo estará a cargo de la entidad que designen los distintos organismos estatales. En el caso del poder ejecutivo, la propia ley asigna esta función a la Contraloría General de la Unión. Solo quienes consten en esta lista podrán solicitar ser recibidos en audiencia pública por los funcionarios del poder ejecutivo, legislativo y judicial. 


\subsection{Registros mixtos}

En la legislación chilena, peruana y en el proyecto de ley que se debate en Colombia se combinan los dos tipos de registros. En este modelo, los altos cargos públicos están obligados a informar y publicar las reuniones mantenidas, lo que también implica que el sujeto privado con el que se llevó a cabo ese contacto queda automáticamente apuntado en el registro de lobistas.

Los artículos 6 y 7 de la Ley 20730 chilena disponen la creación de un registro de agenda pública en el que deberán constar las audiencias que tengan por objeto el lobbying o la "gestión de intereses", el lobistas o gestor de intereses y en representación de quien actuó; la individualización de los asistentes; si el interlocutor percibe una remuneración por dicha actividad; el lugar, la fecha y la materia tratada. Así mismo, se deberán registrar los viajes realizados en el ejercicio de las funciones públicas, el destino, el objeto, el costo total y la persona natural o jurídica que lo financió; y los donativos oficiales y regalos protocolares, la fecha de recepción, la ocasión y la persona natural o jurídica de la cual procede.

La información deberá estar disponible en las páginas institucionales de los organismos donde laboren cada uno de los sujetos pasivos y se deberá actualizar al menos una vez al mes. Estas instituciones también deberán llevar un registro público de lobistas y gestores de intereses. La inscripción podrá realizarse a solicitud expresa de estos actores o automáticamente una vez que se efectúen actividades de lobbying. Así mismo, el Consejo para la Transparencia debe administrar un sitio web específico para publicitar estos datos. La única excepción a la obligación de publicar serán las actividades que involucren la seguridad nacional sobre las cuáles se deberá informar de forma reservada al Contralor General.

La Ley también obliga al Consejo de Transparencia a llevar una lista de lobistas y gestores de intereses que hayan sostenido reuniones con los sujetos regulados del poder ejecutivo, los consejos autónomos y las fuerzas de seguridad. De igual manera, dispone que las demás instituciones que tengan funcionarios obligados por este cuerpo normativo celebren convenios con dicha dependencia para facilitar esta información. Esta nómina incluirá los mismos datos exigidos en los registros de audiencias y se actualizará trimestralmente. En esta misma línea, la Ley 28024 de Perú prevé la obligación, a los funcionarios abarcados en su ámbito de aplicación, de dejar constancias de las comunicaciones 
que tengan con los gestores de intereses. No obstante, se remite a los reglamentos la atribución de regular los instrumentos para garantizar el cumplimiento de este deber. En contraste, el título IV de este cuerpo normativo sí dispone directamente la creación de un Registro Público de Gestión de Intereses y determina las reglas de su funcionamiento.

El Registro Público de Gestión de Intereses está a cargo de la Superintendencia Nacional de Registros Públicos (SUNARP). La inscripción en el mismo es obligatoria para quienes quieran realizar estas actividades. Sin embargo, la gratuidad del registro no está garantizada por la Ley. Al contrario, esta prevé expresamente que estará sujeta al pago de derechos. El número registral dura dos años, posteriormente podrá renovarse conforme lo que disponga el reglamento. Todos los actos realizados relacionados con el lobbying deben reportase de forma obligatoria.

El Registro debe incluir los datos de la persona natural o jurídica que actúa como gestor de intereses; la información sobre la relación jurídica entre el gestor profesional y la persona beneficiada, de ser el caso; la descripción general de las actividades realizadas en este contexto; la identificación de los funcionarios con los que se interactúa en este marco; la constancia de los actos realizados emitida por servidores públicos contactados; y cualquier otra información que dispongan los reglamentos. La SUNARP deberá publicar este registro en las distintas páginas de internet y definir otros mecanismos de difusión para ampliar su alcance. No obstante, no se prevé la obligación de crear un sitio web específico.

Así mismo, los gestores de intereses deben presentar un informe cada seis meses que deberá contener un breve resumen del objeto, medios empleados y funcionarios públicos contactados; y cualquier otra información precisada en el respectivo reglamento. Por su parte, la SUNARP deberá remitir este informe a la Contraloría General de la República. Toda la información provista por los gestores de intereses será considerada declaración juramentada, por lo que su falseamiento tendría consecuencias penales.

El modelo regulatorio que se propone en el proyecto de ley colombiano es similar al chileno. Lo que se pretende es crear un Registro Público de Cabilderos y Actividades de Cabildeo (RPC). La información contenida en este instrumento es el nombre de cabildero, identificación, domicilio, dirección, teléfono y correo electrónico corporativos y de, ser persona jurídica, debe incluir el certificado de existencia 
legal y la representación legal; los mismos datos de sus clientes, además de la descripción general de las actividades y el área de intereses de estos. Así mismo, los lobistas deben detallar los asuntos en los que representaron a cada cliente y las personas naturales que ejercieron la actividad, si el cabildero es una persona jurídica.

Según la propuesta normativa, el RPC será administrado por la entidad que designe el Gobierno Nacional y deberá ser publicado en una página de internet propia. El organismo encargado de esta función presentará un reporte anual al Congreso y capacitará a los grupos sociales, particularmente a los que tienen una especial protección constitucional, en el acceso a esta información. El Proyecto de Ley prevé el principio de máxima publicidad. Por lo tanto, esta dependencia deberá procurar que estos datos sean conocidos por el máximo número de ciudadanos de manera comprensible, suficiente y oportuna.

Las autoridades públicas no podrán participar en actividades de cabildeo con sujetos que no se encuentren registrados en el RPC. Así mismo, el constar en este registro no obliga a los funcionarios a reunirse con los lobistas. Sin embargo, el Proyecto Normativo sí establece el principio de igualdad de trato para todos los "grupos de interés".

La obligación de registrar un contacto en el RPC es de los cabilderos. No obstante, las autoridades deberán validar esta información, verificar el cumplimiento y de constatar una omisión notificar a la entidad encargada de la administración del Registro. También es un deber de los funcionarios publicar las visitas recibidas en su despacho con hora, fecha y tema a tratar.

\subsection{Registros de viajes y regalos}

Otro instrumento relevante en la regulación del lobbying es la obligación de registrar los regalos que reciben los funcionarios por parte de los lobistas y los viajes que realizan financiados por estos. Este modelo se aplica en Chile y se pretende implementar en Colombia mediante el Proyecto de Ley para regular el cabildeo. Sobre este tema, otra de las posibilidades es directamente prohibir a los cargos públicos aceptar este tipo de obsequios. Por esta opción se opta en la legislación peruana y ecuatoriana. 
Los artículos 6 y 7 de la Ley 20730 chilena disponen que los sujetos obligados incluyan, en sus registros respectivos, los viajes realizados en el ejercicio de las funciones públicas, el destino, el objeto, el costo total y la persona natural o jurídica que lo financió; y los donativos oficiales y regalos protocolares, la fecha de recepción, la ocasión y la persona natural o jurídica de la cual procede.

Al igual que en Chile, de aprobarse el proyecto de ley que lo crea, el RPC colombiano deberá contemplar un registro de los viajes financiados por los cabilderos. Mediante este instrumento los cargos públicos informarán el destino de los viajes, los eventos a los que asistan, el costo total de los mismos y la persona que los financió.

A diferencia de la experiencia chilena y colombiana, la Ley 28024 de Perú prohíbe a los funcionarios y a su cónyuge aceptar de forma directa o indirecta cualquier liberalidad de parte de los gestores de intereses o de los terceros que representen. Este cuerpo normativo entiende por liberalidad los obsequios, donaciones, servicios gratuitos u ofertas de empleo.

No obstante, la Ley prevé, como excepciones a la prohibición de recibir obsequios, las donaciones lícitas para campañas políticas; los legados y donaciones a favor del Estado; las materiales con información relevante para el beneficiario de la gestión como, por ejemplo, libros o revistas; las invitaciones a capacitaciones que puede incluir el pago del transporte, hospedaje y alimentación, siempre que esto sea debidamente sustentado y aprobado por el titular de pliego de las instituciones públicas y; los reconocimientos o premios conferidos en concursos o eventos abiertos al público, mientras solo tengan valor conmemorativo; y las muestras distribuidas con fines promocionales.

En Ecuador, al igual que en Perú, el literal k) del artículo 24 de la Ley Orgánica de Servicio Público (LOSEP) ${ }^{38}$ prohíbe, a todos los servidores públicos, "solicitar, aceptar o recibir, de cualquier manera, dádivas, recompensas, regalos o contribuciones en especies, bienes o dinero, privilegios y ventajas, en razón de sus funciones para sí sus superiores o de sus subalternos".

38 Ecuador. (2010, octubre 6).Ley Orgánica de Servicio Público. R.O Suplemento 294. 


\subsection{Huella de cabildeo}

Este mecanismos, creado en el Proyecto de Ley colombiano, consiste en la obligación de publicar el listado de los "grupos de interés" que intervienen en el proceso de elaboración de las leyes, otras normas jurídicas y actos administrativos, como parte de su motivación.

\subsection{Implementación de la regulación}

La implementación de la regulación del lobbying en los países analizados ha presentado cierta dificultad. Por ejemplo, en Perú, en el Listado Nacional de Gestión de Intereses, publicado por la SUNARP en su página de internet y que se actualiza semestralmente, únicamente constan seis personas naturales ${ }^{39}$. Claramente, los actores que realizan actividades que se encuadran en la definición de "gestión de intereses", prevista en la legislación peruana, no se agotan en los que constan en el listado.

En Colombia, el registro creado por la Resolución MD-2348 se encuentra publicado en la página de internet de la Cámara de Representantes. Para el periodo 2014-2018 únicamente se encuentran acreditados 27 sujetos, de lo cuáles solo 13 presentan información de contacto ${ }^{40}$.

En Argentina, la eficacia del Decreto 1172/2003 es limitada. Por ejemplo, la Subsecretaria para la Reformar Institucional y el Fortalecimiento de la Democracia, el organismo dependiente de la Jefatura del Gabinete encargado de implementar el registro de audiencias y agendas de los altos cargos del poder ejecutivo, inicialmente logró crear un sitio de internet en el que se publicaba esta información. Sin embargo, no se llegó a incorporar a todos los sujetos obligados y en el año 2009, cuando esta entidad fue suprimida, también se desactivo la página web institucional $v$.(Novaro, 2015). Actualmente, este registro se encuentra disponible en internet y es de acceso público ${ }^{41}$.

39 Superintendencia Nacional de Registros Públicos. Listado Nacional de Gestión de Intereses. Página de internet: https://www.sunarp.gob.pe/transparencia.asp?ID=1403. Consultado: 23 de abril del 2018.

40 Colombia. Registro Público de Cabilderos para el período 2014-2018. Página de internet: http:://www.camara.gov.co/registro-publico-de-cabilderos-datos-de-contacto.

41 Secretaría de Reforma Insitucional y Fortalecimiento de la Democracia. Registro Único de Audiencias de Gestión de Intereses. Página de internet://audiencias.mininterior.gob.ar/. Consultado: 1 de mayo del 2018. 
Pese a las dificultades en la implementación del Registro Único de Audiencias de Gestión de Intereses, este instrumento fue utilizado por los medios de comunicación para conocer datos relevantes relacionados con casos de presunta corrupción. Por ejemplo, mediante este mecanismo quedaron registradas las reuniones que los miembros del Gobierno argentino tuvieron con la empresa constructora brasileña Odebrecht y los temas tratados en cada una de ellas v.(Indart, 2017).

En Chile, en la actualidad existe una página de internet creada exclusivamente para la publicación de la información dispuesta por la Ley 20730. En el registro de sujetos activos consta más de dos mil cuatrocientos lobistas y gestores de intereses vigentes y tan solo uno no vigente. En el 2017, fueron registradas veintitrés audiencias y en lo que va del 2018 constan quince. En cuanto a los viajes, el sitio de internet informa sobre veintiséis realizados el año 2017 y 30 en lo que va del 2018. Sobre donativos, se contabilizan 12 en todo el 2017 y 6 en lo que va del 2018. Los datos están disponibles desde el $2014^{42}$.

Aunque las cifras señaladas anteriormente reflejan que aún no se encuentran registradas todas las actividades que deberían constar, la Ley 20730 va alcanzando progresivamente un nivel de implementación cada vez mayor. Desde la doctrina se destaca que el Cuerpo Normativo es un aporte para la democratización de las relaciones entre el sector privado y el sector público, ya que ha ampliado la diversidad de los actores que se reúnen con los funcionarios v.(Sahd y Valenzuela, 2017).

\section{CONCLUSIONES}

El debate teórico revisado sobre la legitimidad del lobbying refleja que, pese a que la transparencia no es suficiente para eliminar las asimetrías estructurales entre los actores de la sociedad civil, aporta para evitar que esta actividad sea una forma de evadir los controles democráticos y el escrutinio público. Por lo tanto, la regulación podría atenuar las contradicciones entre los mecanismos participativos y la democracia.

El análisis de la experiencia comparada en otros países de Sudamérica refleja que, si bien existen problemas con la implementación de los mecanismos para regular el lobbying y el cumplimiento de las nor-

42 Registro de Público de Lobistas y Gestores de Intereses Particulares. Página de internet: http://web.uchile.cl/transparencia/leylobby/registrosujetosactivos.html 
mas jurídicas que los prevén no son completas, estos tienen efectos positivos que aportan a la legitimidad de esta actividad, o al menos, atenúan los efectos nocivos de realizarla de forma opaca.

El ordenamiento jurídico ecuatoriano contiene diversos instrumentos que buscan la participación de la sociedad civil en los procesos de toma de decisiones públicas. Sin embargo, estos no son suficientes para transparentar el lobbying que se dan entre estos actores y los funcionarios públicos por fuera de los mecanismos institucionales. A excepción de la prohibición de recibir regalos, la legislación de Ecuador carece de los demás instrumentos regulatorios con los que cuentan países como Chile, Perú, Colombia y Argentina. En consecuencia, es recomendable que el legislador ecuatoriano tome en cuenta la experiencia comparada e implemente normas jurídicas que regulen la "gestión de intereses".

\section{REFERENCIAS BIBLIOGRÁFICAS}

Arbia, C. (2017). Proyecto "House Of Cards": los 6 aspectos de la ley para regular el lobby empresarial en Argentina. Infobae. Recuperado de: https://www.infobae.com/economia/2017/05/30/proyecto-houseof-cards-los-6-aspectos-de-la-ley-para-regular-el-lobby-empresarialen-argentina/.Consultado: 20 de febrero del 2018.

Comisión de las Comunidades Europeas. (2001). La Gobernanza Europea: Un Libro Blanco.

Córdova, D. (2017). Análisis comparado de la regulación del lobby en Iberoamérica: de la transparencia de los intereses en las decisiones públicas (Tesis Doctoral) .Universidad Complutense de Madrid. Madrid. Recuperado de: http://eprints.ucm.es/40971/1/T38308.pdf. Consultado: 11 de noviembre del 2017.

Cristaldo, H., y Brito, D. (2017). Diputados brasileños discuten lobby y muertes en el tránsito. Agencia Brasil. Recuperado de: http://agenciabrasil.ebc.com.br/es/politica/noticia/2017-12/diputados-brasilenos-discuten-lobby-y-muertes-en-el-transito. Consultado: 5 de abril del 2018. 
Dates, L. y Sama, F. (2017). El Lobby (o gestión de intereses) en Argentina. Comentarios al Proyecto de ley del Poder Ejecutivo Nacional. Recuperado de: http://www.abogados.com.ar/el-lobby-o-gestion-de-intereses-en-argentina-comentarios-al-proyecto-de-ley-del-poder-ejecutivo-nacional/19957

European Comission for Democracy Through Law. (2013). Report On The Role Of Extra-Institutional Actors In The Democratic System ( Lobbying ) adoptado por la Comisión de Venecia en su Sesión Plenaria No.94 ( Venecia ).

Indart, R. (2017). Cómo fueron las 23 reuniones de Odebrecht con la gestión K. Recuperado de: http://www.perfil.com/politica/como-fueron-las-23-reuniones-de-odebrecht-con-la-gestion-k.phtml

Kumar, K. (1993). Civil Society: An Inquiry into the Usefulness of an Historical Term. The British Journal of Sociology, Vol 44. No.3, pp.375-395.

Novaro, M. (2015). Regulación de lobbies en Argentina. Centro de Investigaciones Políticas Policy paper No. 4. Instituto de Investigación en Ciencias Sociales Universidad Diego Portales.

Pacheco, P. (2012). Experimentalismo Democrático, Nuevas Formas De Regulación y Legitimación Del Derecho. Democratic Experimentalism, New Forms of Regulation and Legitimation of Law, No.46, pp.37-68.

Puentes, M. y Suarez, I. (2016). Un acercamiento a Gramsci: la hegemonía y la reproducción de una visión del mundo. Revista Colombiana de Ciencias Sociales, pp. 449-468.

OECD. (2013). Transparancy and integrity in lobbying, pp.1-6. Recuperado de: https://doi.org/10.1787/gov_glance-2015-35-en. Consultado: 11 de noviembre del 2017.

Ridao, J. (2017). Los Grupos De Presión. Barcelona: Centre d' Estudis Jurídcs i Formació Especialitzada.

Rubio, R. (2007). Los Ciudadanos ¿Protagonistas de la Globalización?. Recuperado de: http://www.rafarubio.es/wpcontent/uploads/Ciudadanosprotagonistasglobalizacion.pdf. Consultado: 10 de noviembre del 2018. 
Sahd, J. y Valenzuela, C. (2017). Lobby Regulation in Chile: a Pathway toward Reducing Inequality. OECD Global Anti-Corruption and Integrity Forum. Recuperado de: https://www.oecd.org/cleangovbiz/Integrity-Forum-2017-Sahd-Valenzuela-Lobby-Regulation-Chile.pdf

Sousa Santos, B. y Rodríguez Garavito, C. (2007). El derecho, la política y lo subalterno en la globalización contrahegemónica. En B. Sousa Santos. (Ed.).El derecho y la globalización desdes abajo: hacia una legalidad cosmopolita (pp. 7-27). Cuajimalpa: Anthropos.

Taylor, C. (1995). Invoking Civil Society. In Philosophical Arguments (pp. 204-224). Harvard University Press.

Recibido: 22 de septiembre de 2018

Aceptado: 3 de noviembre de 2018

Mtr. Víctor Augusto Espinosa Jácome: Investigador Jurídico Independiente.

Correo electrónico: victoraugusto@94hotmail.com 